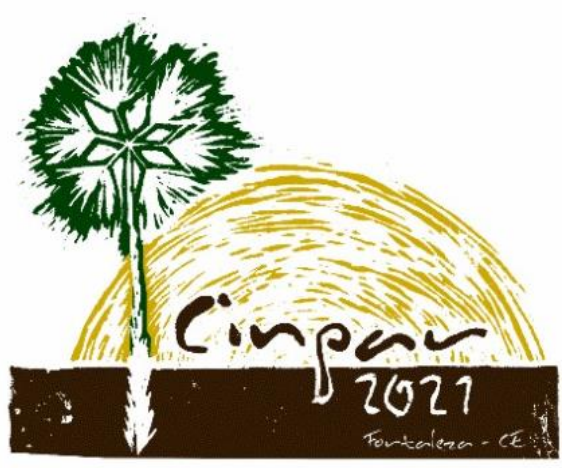

XVII Congresso Internacional sobre Patologia e Reabilitação das Construções

XVII Congreso Internacional sobre Patología y Rehabilitación de las Construcciones

XVII International Conference on Pathology and Constructions Rehabilitation

FORTALEZA (Brasil), 3 a 5 de junho de 2021

https://doi.org/10.4322/CINPAR.2021.120

\title{
Influência do Tempo nas Manifestações Patológicas em Residências Populares
}

\section{Influence of the Time on the Pathological Manifestations in Popular Residences}

\author{
Gabriel Teles NOLASCO ${ }^{1}$, Juliana Barbosa dos SANTOS², Yuri Sotero Bomfim FRAGA ${ }^{3}$ \\ ${ }^{1}$ Centro Universitário Euro-Americano (UNIEURO), Brasília/DF, Brasil, gabriel38129@unieuro.com.br \\ ${ }^{2}$ Centro Universitário Euro-Americano (UNIEURO), Brasília/DF, Brasil, juliana.barbosa2619@gmail.com \\ ${ }^{3}$ Centro Universitário Euro-Americano (UNIEURO), Brasília/DF, Brasil, yurisotero.engcivil@gmail.com
}

\begin{abstract}
Resumo: O programa "Minha Casa Minha Vida" (MCMV) teve início em 2009, com o intuito de diminuir a dificuldade habitacional da população brasileira e facilitar a aquisição da casa própria. O tempo de vida útil de uma edificação depende de vários fatores, como materiais utilizados, procedimentos executivos, projetos, modo de uso, entre outros. Alguns fatores contribuem para o surgimento de manifestações patológicas como a mão de obra que nem sempre é especializada, falhas na etapa de execução e uso de materiais de baixa qualidade. A presente pesquisa tem como objetivo verificar a influência do tempo nas manifestações patológicas de edificações do Programa MCMV. A metodologia utilizada consistiu em entrevistas com moradores e visitas in loco em condomínios habitacionais populares com diferentes idades de construção situados nos municípios de Cidade Ocidental-GO, Valparaíso de Goiás-GO e Recanto das Emas-DF para vistoria e relatórios fotográficos. Foi feito um tratamento de dados e montagem da matriz GUT para as áreas internas e externas dos condomínios inspecionados. A edificação mais jovem apresentou poucas manifestações patológicas em relação a edificação mais velha, mostrando que a idade da edificação contribui para o aparecimento de manifestações patológicas, tendo em vista que a edificação mais velha apresentou um número significativo de problemas.
\end{abstract}

Palavras-chave: Manifestações patológicas; GUT; Residências populares.

\begin{abstract}
The "Minha Casa Minha Vida" (MCMV) program started in 2009, with the aim of reducing the housing difficulties of the Brazilian population and facilitating the acquisition of a home. The lifespan of a building depends on several factors, such as materials used, executive procedures, projects, mode of use, among others. Some factors contribute to the emergence of pathological manifestations such as labor that is not always specialized, failures in the execution stage and the use of low-quality materials. This research aims to verify the influence of time on the pathological manifestations of buildings in the MCMV Program. The methodology used consists of identifying with locations and visits in loco in popular housing condominiums with different ages of construction located in the cities of Cidade Ocidental-GO, Valparaíso de Goiás-GO and Recanto das Emas-DF for inspection and photographic reports. Data processing and assembly of the GUT matrix was carried out for the internal and external areas of the inspected condominiums. The youngest building showing very few pathological manifestations in relation to the older building, showing that the age of the building contributes to the appearance of pathological manifestations, considering that the older building presented a significant number of problems.
\end{abstract}

Keywords: Pathological manifestations; GUT; Popular residences. 


\section{Introdução}

As manifestações patológicas são problemas encontrados em diversas edificações. São exemplos de manifestações patológicas as fissuras, deterioração das estruturas de concreto, manchas, eflorescência, corrosão de armadura, etc. Segundo Silveira Neto (2005), as manifestações podem aparecer por causa de materiais de baixa qualidade, mão de obra não qualificada, projetos com erros, mudança no uso dessas edificações depois da conclusão da obra, uso inadequado pelo dono do imóvel e falta de manutenção.

Segundo Sena et al. (2020), as manifestações patológicas podem ser divididas em dois grupos: os simples e os complexos. Os simples podem ser analisados através de uma padronização, sendo mais evidentes a "olho nu" e não necessitando tanta experiência do profissional responsável. Um exemplo que pode ser dado é a corrosão de armaduras em um pilar, causado pela falta de cobrimento nas armaduras e/ou baixa qualidade do concreto utilizado. Os complexos são aqueles que necessitam de um profissional com conhecimentos aprofundados e uma investigação profunda do problema encontrado com a utilização de equipamentos que possam aferir e dizer a origem na manifestação. Pode-se citar como exemplo a umidade, pois o local onde se mostra a manifestação patológica nem sempre é o local de origem, sendo necessário uma investigação mais apurada.

O programa "Minha Casa Minha Vida" (MCMV) foi criado para atender as necessidades básicas de habitação da população de baixa renda. O programa funciona por meio da concessão de financiamento ao beneficiário organizado de forma associativa por uma entidade organizadora e com recursos provenientes do Orçamento Geral da União - OGU, apontados ao Fundo de Desenvolvimento Social - FDS.

De acordo com Silveira Neto (2005), uma edificação necessita de manutenção ao longo de sua vida útil. A cada manutenção é possível recuperar parte do desempenho perdido da edificação, podendo ser uma manutenção preventiva que visa corrigir o erro antes de acontecer e manutenção corretiva que é feita quando há o aparecimento da manifestação patológica. Apesar disso, grande parte dos moradores desses conjuntos habitacionais populares não tem condições de fazer reparos regulares, o que agrava o surgimento das manifestações patológicas.

Os moradores de edificações do MCMV têm mostrado que essas casas apresentam manifestações patológicas dos mais diversos tipos. Segundo Queiroga e Aquino Filho (2018), dados obtidos através de modelagens estatísticas mostram que as manifestações presentes nessas edificações são originadas de erros na fase de projeto e execução, livrando os moradores da culpa pelo surgimento dessas manifestações patológicas. Isso reflete nas edificações, pois certamente haverá redução da vida útil da edificação. Hoje o número de reclamações em relação a essas casas e pessoas arrependidas de terem comprados são enormes, pois viver em uma casa onde há presença de manifestação patológica reflete significativamente na qualidade de vida do proprietário.

Segundo Costa et al. (2020), uma das metodologias utilizadas para analisar as manifestações patológicas é a Matriz GUT, que foi criada na década de $80 \mathrm{com}$ o intuito de classificar problemas e, com isso, classificá-los de acordo com uma ordem de prioridade. Essa metodologia é simples de utilizar, basta construir uma tabela com os problemas e analisar os fatores de Gravidade, Urgência e Tendência atribuindo nota de 1 a 5. Posteriormente, os fatores são multiplicados e os resultados são ordenados em ordem decrescente, ou seja, a maior prioridade é o maior valor obtido.

Diante do exposto, esta pesquisa visa verificar o efeito do tempo no surgimento de manifestações patológicas em residências do programa MCMV utilizando a matriz GUT.

\section{Metodologia}

O presente estudo é caracterizado como uma pesquisa aplicada qualitativa que visar compreender o assunto através de coleta de dados. Uma pesquisa é aplicada quando envolve verdades e interesses locais, com o objetivo de gerar conhecimentos para aplicação prática e dirigidos à solução de problemas específicos (SILVA; MENEZES, 2005).

Foram realizadas visitas em três condomínios, denominados de Condomínio A, Condomínio B e Condomínio C. $O$ critério de escolha dos condomínios foi feito por meios de: 
- tempo da construção, com diferentes idades de construção;

- não havendo reformas recentes;

- obrigatoriamente fazendo parte do programa MCMV.

O condomínio A possui 2 anos de construído. Ele está localizado na Cidade Ocidental e possui 6 blocos, com 16 apartamentos em cada bloco com 4 apartamentos em cada pavimento, totalizando 4 pavimentos por bloco. O condomínio conta com uma área de lazer com churrasqueira, estacionamento privativo e uma quadra de esportes.

O condomínio B possui 5 anos de construído e está localizado na cidade de Valparaíso de Goiás-GO. Ele possui 2 blocos, com 16 apartamentos em cada bloco, sendo 8 apartamentos em cada pavimento, totalizando 2 pavimentos por bloco. 0 condomínio conta com uma área de lazer com churrasqueira, estacionamento privativo e uma quadra de esportes.

O condomínio C foi construído há 7 anos e está localizado na cidade de Recanto das Emas. Ele possui 8 blocos, com 16 apartamentos em cada bloco. O condomínio tem uma área de lazer com churrasqueira, estacionamento privativo e uma brinquedoteca.

Durante as inspeções foi aplicado aos moradores um questionário para coletar informações. Além disso, foi feito um registro fotográfico das manifestações patológicas, como mostrado nos Apêndices $A$, B e C. Posteriormente foram listados os problemas e foram conferidos a eles notas dos fatores Gravidade (G), Urgência (U) e Tendência ( $T$ ). Com isso foi calculado o número GxUxT para saber identificar o grau de priorização para realização de terapia das manifestações patológicas encontradas.

\section{Resultados e Discussão}

Nesta etapa são apresentadas e discutidas as manifestações patológicas encontradas nos condomínios durante as inspeções na parte interna e externa. A parte interna se refere aos apartamentos e a parte externa se refere às áreas não privativas como área de lazer e fachada.

\subsection{Condomínio A}

Durante a realização da inspeção nesse condomínio, com 2 anos de construído, foi mencionado pelos moradores que nenhum dos apartamentos foi entregue com cerâmica no piso, incluve em suas áreas molhadas, tendo que ser colocado pelos moradores posteriormente. Em entrevista com alguns moradores foi relatado que a construtura responsável utilizou materiais de baixa qualidade, como portas, torneiras e cerâmicas, sendo necessário realizar a troca após a mudança para os apartamentos. A Figura 1 apresenta alguma das manifestações patológicas encontradas.

(A)

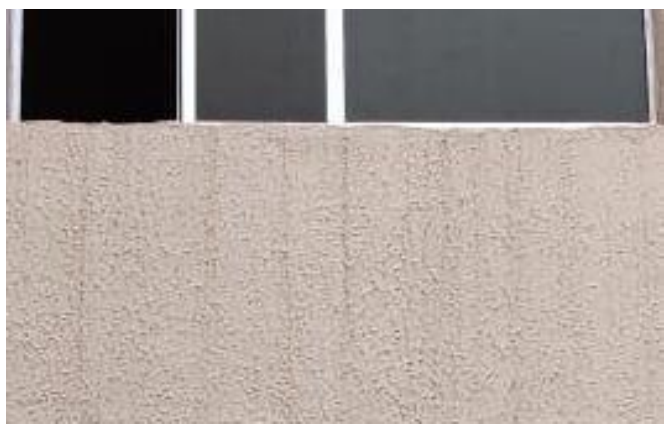

(B)

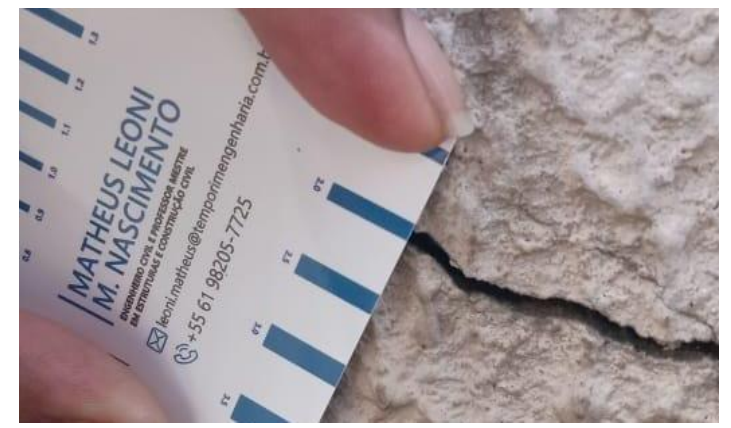

Figura 1 - (A) Manchas na fachada do bloco A; (B) Trinca na sala de estar

Algumas das manifestações patológicas encontradas foram a existência de manchas nas paredes do bloco A devido à falta de pingadeira, como pode-se ver na Figura 1(a). Observa-se na Figura 1(b) que foram encontradas trincas perto das extremidades da sala de um apartamento do segundo andar. Pode-se observar na Quadro 1 o grau de priorização da área interna do condomínio $A$. 
Quadro 1 - Grau de priorização da área interna do condomínio A

\begin{tabular}{|c|c|c|c|c|c|}
\hline Patologia & G & U & T & GUT= GxUxT & $\begin{array}{c}\text { Grau de } \\
\text { priorização }\end{array}$ \\
\hline $\begin{array}{c}\text { Trincase } \\
\text { fissuras }\end{array}$ & 2 & 1 & 1 & 2 & 1 \\
\hline $\begin{array}{c}\text { Sujidade e } \\
\text { Mancha de } \\
\text { escorrimento } \\
\text { de agua }\end{array}$ & 1 & 1 & 1 & 1 & 2 \\
\hline
\end{tabular}

No condomínio A, o pior caso interno apontado pelo GUT foi a presença de trincas e fissuras, com nota 2, sendo esta localizada na sala em um dos apartamentos. A apresentação dessa manifestação patológica chama a atenção por ser um condomínio recentemente construído.

A área externa do condomínio conta com uma área de lazer equipada com uma área para eventos. $\mathrm{Na}$ inspeção foram encontradas fissuras, manchas nas fachadas, manchas escuras nos cantos das janelas expostas e manchas na laje de acesso à cobertura como mostrado na Figura 2.

(A)

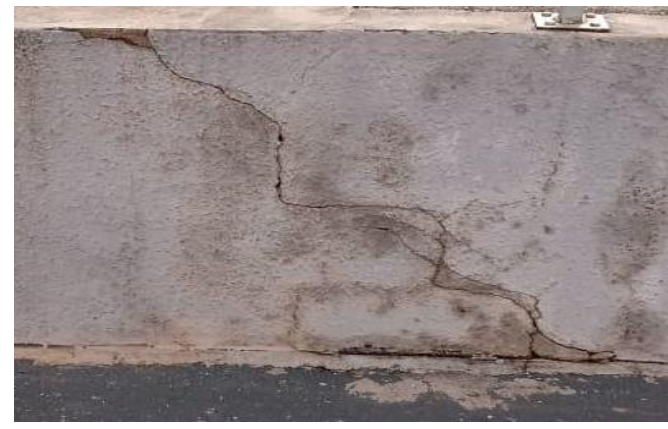

(B)

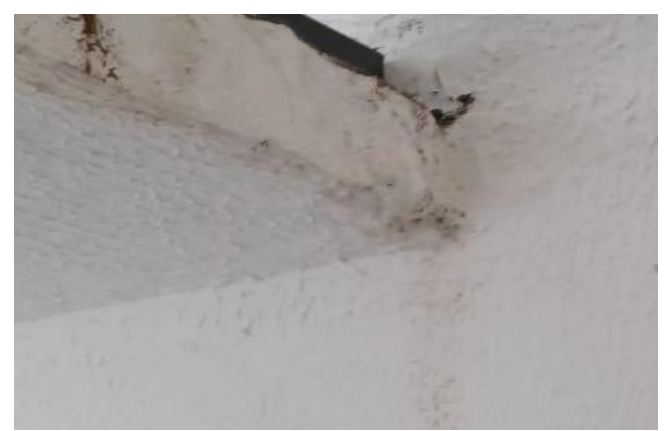

Figura 2 - (A) Fissuras no estacionamento; (B) Mancha por falha na impermeablização da manta da laje que da acesso à cobertura

A Figura 2(a) se refere a fissuras encontradas no estacionamento desse condomínio. A Figura 2(b) se refere a existência de manchas causadas por falha na impermeabilização da manta da laje que da acesso a cobertura do prédio, ficando este problema evidente em períodos chuvosos, provocando essa mancha. Pode-se observar no Quadro 2 o grau de priorização da área externa do condomínio $A$.

Quadro 2 - Grau de priorização da área externa do condomínio A

\begin{tabular}{|c|c|c|c|c|c|}
\hline Patologia & G & U & T & GxTxU & Grau de Prioridade \\
\hline Fissuras & 2 & 2 & 2 & 8 & 1 \\
\hline $\begin{array}{c}\text { Manchas nos cantos } \\
\text { das janelas }\end{array}$ & 2 & 1 & 1 & 2 & 2 \\
\hline Manhas da fachada & 1 & 1 & 1 & 1 & 3 \\
\hline
\end{tabular}

O pior caso na área externa apontado pelo GUT são as fissuras, com nota 8. Na gravidade, foi realizado a classificação "pouco grave", sendo atribuída nota 2, pois os danos são mínimos para o condomínio. No item urgência, a classificação foi "pouco urgente", também sendo atribuída nota 2, pois o problema pode esperar um pouco. Na tendência, foi classificada como podendo o caso piorar a longo prazo, sendo definida a nota 2. 


\subsection{Condomínio B}

O condomínio B com idade de 5 anos apresentou algumas manifestações patológicas, sendo que predominou em todos os apartamentos inspecionados a existência de fissuras. Embora apresenta-se um grau elevado de manifestações patológicas, segundo os moradores a construtora realiza manutenções corretivas quando solicitado. Este condomínio foi entregue com revestimento cerâmico em todos os apartamentos. Foram encontradas algumas manifestações patológicas na área interna, como mostrado na Figura 3.

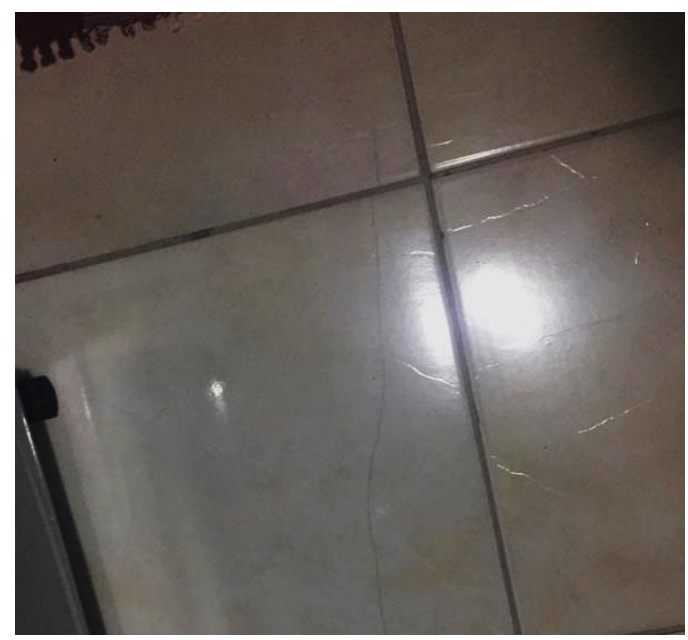

Figura 3 -Fissuras nas cerâmicas na cozinha

A Figura 3 mostra fissuras nas cerâmicas com $37 \mathrm{~cm}$ de comprimento em uma das cozinhas do apartamentos visitados. Esse problema foi encontrado em 4 apartamentos, sendo necessária a sua troca. Pode-se observar no Quadro 3 o grau de priorização da área interna do condomínio B.

Quadro 3 - Grau de priorização da área interna do condomínio B

\begin{tabular}{|c|c|c|c|c|c|}
\hline Patologia & G & U & T & GUT= GxUxT & Grau de priorização \\
\hline Trincas nas cerâmicas & 2 & 1 & 1 & 2 & 4 \\
\hline Desplacamento das cerâmicas & 2 & 2 & 2 & 8 & 2 \\
\hline Fissuras & 2 & 1 & 1 & 2 & 3 \\
\hline Mofo na área de lazer & 4 & 3 & 3 & 36 & 1 \\
\hline
\end{tabular}

No condomínio $\mathrm{B}$, os piores casos da parte interna foram o mofo na área de lazer e o desplacamento das cerâmicas, com notas GUT 36 e 8, respetivamente. Dessa forma, deve ser feita a retirada da cerâmica e a colocação da mesma com material e mão de obra de qualidade, visto que o morador citou que esse problema é recorrente, já que houve a retirada, mas o problema voltou a aparecer. De acordo com a nota GUT, o mofo na área de lazer pode ser classificado como "muito grave", pois pode causar sérios danos à edificação. No item urgência, a classificação foi "urgente", pois o problema deve ser solucionado rapidamente. $\mathrm{Na}$ tendência, foi classificada como podendo o caso piorar a médio prazo.

Esse condomínio conta com uma área de lazer equipada com uma mini quadra de futebol, que foi concebida pelos próprios moradores há 1 ano, e uma área para eventos. A Figura 4(a) apresenta a única manifestação patológica encontrada. Na Figura 4(b) destaca-se um problema que pode resultar no surgimento de manifestações patológicas. 
(A)

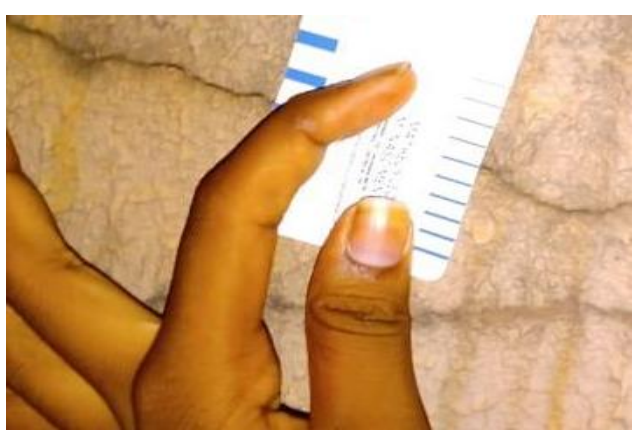

(B)

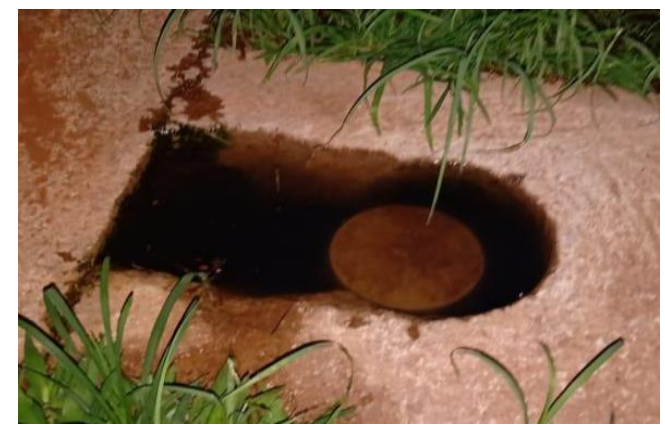

Figura 4 - (A) Fissuras na parede de entrada; (B) esgoto entupido no estacionamento

A Figura 4(a) apresenta uma fissura presente no muro de entrada do condomínio e Figura 4(b) um esgoto entupido que pode resultar no surgimento de manifestações patológicas. Pode-se observar no Quadro 4 o grau de priorização da área externa do condomínio B.

Quadro 4-Grau de priorização da área externa do condomínio B

\begin{tabular}{|c|c|c|c|c|c|}
\hline Patologia & G & U & T & GUT= GxUxT & Grau de priorização \\
\hline Fissuras & 2 & 1 & 1 & 2 & 1 \\
\hline
\end{tabular}

A única manifestação patológica encontrada na área externa do condomínio $B$ foi o aparecimento de fissuras. Apesar disso, ressalta-se que foi encontrado um esgoto entupido, como observado na Figura 4(b), que pode resultar no surgimento de manifestações patológicas no futuro, devendo este problema ser resolvido brevemente.

\subsection{Condomínio C}

Durante a inspeção foram constatados diversos tipos de manifestações patológicas no condomínio C, com 7 anos de idade. Algumas queixas foram feitas pelos moradores como por exemplo o fato da construtora ter utilizado materias de baixa qualidade, sendo necessário refazer a pintura e trocar a cerâmica. A Figura 5 apresenta as manifestações patológicas encontradas na área interna dos apartamentos.

(A)

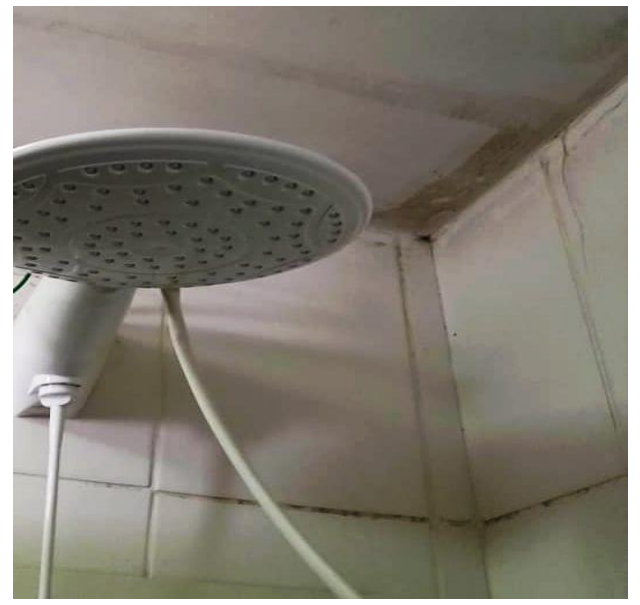

(B)

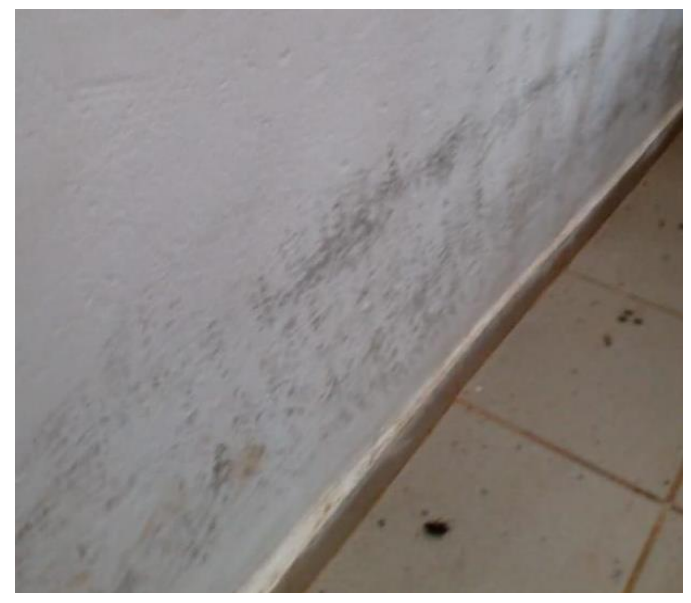

Figura 5 - (A) Eflorescência no banheiro do terceiro andar; (B) Parede mofada na parede do terreo na area de circulação

Como pode-se observar na Figura 5(a) há existência de eflorescência nos banheiros inspecionados. Na Figura 5(b) é possível verificar a existência de mofo na parede do térreo no bloco $\mathrm{C}$ desse condomínio ocasioanda 
por falha na impermeabilização. Pode-se observar no Quadro 5 o grau de priorização da área interna do condomínio C.

Quadro 5 - Grau de priorização da área interna do condomínio C

\begin{tabular}{|c|c|c|c|c|c|}
\hline Patologia & G & U & T & GUT= GxUxT & Grau de priorização \\
\hline Descolamento das cerâmicas & 1 & 2 & 2 & 4 & 6 \\
\hline Mofo no banheiro & 3 & 4 & 4 & 48 & 3 \\
\hline Manchas nos cantos das janelas & 2 & 2 & 2 & 8 & 4 \\
\hline Infiltração nos banheiros & 5 & 4 & 4 & 80 & 1 \\
\hline Fissura nos quartos & 4 & 4 & 4 & 64 & 2 \\
\hline Eflorescência & 2 & 3 & 2 & 12 & 5 \\
\hline
\end{tabular}

O pior caso na área interna apontado pelo GUT é a infiltração nos banheiros com nota 80, necessitando de reparo rápido e de maior atenção. Na gravidade, foi realizado a classificação "extremamente grave", pois os danos podem ser irreversíveis. No item urgência, a classificação foi "urgente", pois o problema deve ser selecionado rapidamente. Na tendência, foi classificada como podendo o caso piorar em curto prazo.

Na parte externa foi possível constatar alguns problemas referentes à construção e ao projeto, visto que um dos blocos foi construído em um nível abaixo dos demais. Sendo assim, quando chove a parte mais baixa fica inundada e causa infiltração na parede desse bloco. Foi constatada uma tentativa de correção na parte inferior das paredes, porém segundos os próprios moradores o problema persiste. A Figura 6 apresenta as manifestações patológicas encontradas na área externa do condomínio C.

(A)

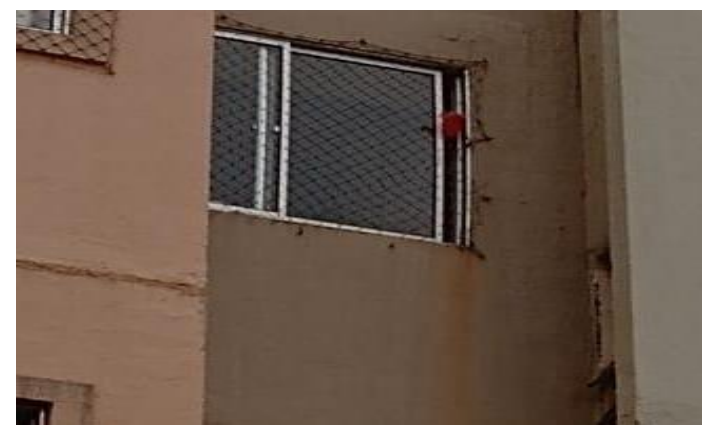

(B)

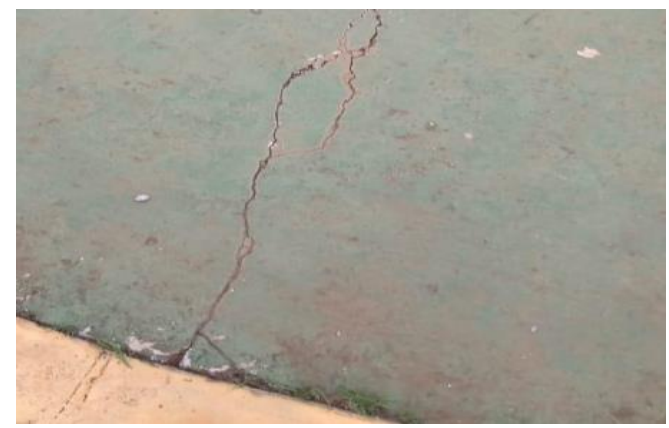

Figura 6 - (A) Mancha no canto da janela da fachada; (B) Fissura na brinquedoteca

Algumas das manifestações encontradas foram manchas dos cantos da janelas como pode ser visto na Figura 6(a), causada por falta de pingadeira. Outra manifestação relatada na Figura 6(b) foi a existência de fissura na brinquedoteca construída pela construtora do condomínio. Outras manifestações econtradas foram a existência de mofo nas fachadas, trincas e fissuras em praticamente todo o condomínio, até mesmo na portaria e na entrada do condomínio. Na área da churrasqueira há manchas na parte inferior das paredes. Pode-se observar no Quadro 6 o grau de priorização da área externa do condomínio C.

Quadro 6 - Grau de priorização da área externa do condomínio C

\begin{tabular}{|c|c|c|c|c|c|}
\hline Patologia & G & U & T & GUT= GxUxT & Grau de priorização \\
\hline Manchas na fachada & 1 & 1 & 1 & 1 & 4 \\
\hline $\begin{array}{c}\text { Infiltração nas paredes do } \\
\text { pavimento superior }\end{array}$ & 5 & 5 & 4 & 100 & 1 \\
\hline Mofo na área de lazer & 5 & 4 & 4 & 80 & 2 \\
\hline
\end{tabular}


O pior caso na área externa, apontado pelo GUT, é a infiltração nas paredes de pavimento superior, com nota 100, necessitando de reparo rápido e de maior atenção. Os prejuízos são extremamente graves e o dano tem potencial para se tornar irreversível, sendo necessária uma ação imediata para correção.

\subsection{Influência do tempo nas manifestações patológicas}

Através dos resultados da matriz GUT, é possível confirmar que o tempo é um dos fatores que contribui no surgimento e agravamento das manifestações patológicas. As fissuras, por exemplo, foram observadas em todos os condomínios, mas com notas e gravidades diferentes. O condomínio C, de maior tempo de construção, apresentou maiores notas GUT e maior quantidade de manifestações patológicas, enquanto o condomínio A com menor tempo de construção apresentou menores notas GUT, consideradas com menores gravidades de manifestações. Esse comportamento pode ser justificado, pois com o decorrer do tempo a construção está sujeita a variações térmicas, expansão dos blocos por umidade, repercutindo na dilatação e contração dos materiais, provocando o aparecimento de fissuras, por exemplo (THOMAZ, 2020).

\section{Conclusão}

A metodologia da matriz GUT permitiu a determinação do grau de priorização das manifestações patológicas de três condomínios de diferentes idades: 2 anos, 5 anos e 7 anos. Tendo em vista os dados apresentados, é possível correlacionar o tempo com o surgimento de manifestações patológicas nas edificações, visto que o condomínio A com idade de 2 anos apresentou uma relação menor no quantitativo de manifestações patológicas, enquanto o condomínio $\mathrm{C}$ com idade de 7 anos apresentou diversas manifestações patológicas. Os tipos de manifestações observadas mudaram conforme o avançar da idade dos condomínios. Enquanto os de menor idade apresentaram problemas relativamentes não graves e com o número GUT menor, nos outros foram constatados problemas com gravidade urgente, apresentando valores de GUT maiores.

Recomenda-se que esta pesquisa seja ampliada para um maior número de edificações e em diferentes cidades e estados para se obter maior precisão na investigação do surgimento de manifestações patológicas em residências populares em diferentes regiões. Dessa forma, a partir de um estudo mais amplo, será possível definir ações para mitigar a ocorrência de manifestações patológicas em habitações de interesse social.

\section{Referências Bibliográficas}

Costa, I. M. D.; Amorim, M. A. B.; Fraga, Y. S. B. (2020). Patologia das construções: estudo de caso em condomínio residencial. IN: Franciele Braga Machado Tullio. (Org). Força, Crescimento e Qualidade da Engenharia Civil no Brasil. 1ed. Ponta Grossa: Atena Editora, v. 1, p. 166-177.

Queiroga, L.A.; Aquino Filho, G.C. (2018). Desempenho de edificações produtos do Programa Minha Casa Minha Vida no Alto Sertão da Paraíba: uma visão de consumidores. 3 Simpósio Paranaense de Patologia das Construções, 47-59.

Sena, G. O.; Nascimento, M.L.M.; Nabut Neto, B.C. (2020). Patologia Das Construções. 1a Edição: 2B Educação. 256 p. ISBN 978-85-54815-83-7.

Silva, E.L.; Menezes, E.M. (2005). Metodologia da Pesquisa e elaboração de Dissertação. 4 ed. Florianópolis: UFSC, 138p.

Silveira Neto, O. (2005). Manifestações patológicas em condomínios habitacionais de interesse social do município de Porto Alegre: levantamento e estudo sobre a recorrência. Dissertação de Mestrado. Escola de Engenharia, Universidade Federal do Rio Grande do Sul, Brasil.

Thomaz, E. (2020). Trincas em edifícios: causas, prevenção e recuperação. São Paulo: Oficina de Texto. 244 p. ISBN 978-65-86235-07-4. 